\title{
Comunicación online: Una sociedad en cambio, activa y conectada
}

\author{
Marcos Sebastián PÉREZ *
}

\section{Una sociedad fragmentada}

Durante las últimas décadas hemos asistido a un proceso creciente de fragmentación de las sociedades desarrolladas y de debilitamiento de sus estructuras y comunidades tradicionales. A su vez, la confianza pública en los gobiernos y en los partidos políticos ha descendido, en un proceso que prima lo individual frente a lo comunitario. Así, se ha ido desarrollando un sistema político de democracia sin ciudadanos en el que los medios de comunicación han conservado un papel valioso, convirtiéndose en auténticos kingmakers, mientras disminuía el de los partidos políticos y el de los votantes. Además, figuras como el spin doctoring han sustituido a la deliberación pública. Los ciudadanos, racionales, abiertos al debate argumental, que seleccionan sus preferencias y realizan selecciones personales, han sido convertidos en consumidores emocionales, seducidos por imágenes dramáticas y que actúan en masa. Asimismo, la comunicación pública (que exige la apertura de vías de participación) ha sido suplantada por la comunicación masiva (que no permite el debate racional). En paralelo, las actuales formulaciones de la democracia representativa priman la opinión pública agregada (en oposición a la opinión pública discursiva), descartando el debate abierto de las políticas públicas, y la argumentación razonada. La opinión pública agregada es un resultado: la suma de juicios individuales a través del voto y de los sondeos. En cambio, la opinión pública discursiva es el proceso de un agente colectivo: el pueblo; en este proceso el público es un colectivo de voluntades individuales que deliberan entre sí, condicionándose mutuamente. Los partidarios de la democracia deliberativa no niegan la existencia de procesos de deliberación pública en las democracias representativas, pero se exige un incremento sustancial.

En la sociedad actual se desfiguran, desaparecen, las fronteras entre medios y política. Por ello, hablamos de la mediatización de la política, término diferente a la natural y neutral mediación; la política mediatizada es la que ha perdido su autonomía y son los medios los que deciden quién accede a la esfera pública. La política funciona cada vez más como realidad virtual en la que las percepciones son todo lo que importa; de este modo, los gobernantes se dedican a gestionar la opinión pública en lugar de gestionar la realidad. De este modo, el mundo elaborado por los medios se convierte, simultáneamente, en representación y referente de sí mismo, en un discurso construido con base en pseudoeventos y noticias prefabricadas. Como adelantó Boorstin hace décadas, el éxito de los pseudoeventos tiene su origen en nuestras extravagantes expectativas: "we expect new heroes every season, a literary masterpiece every month,

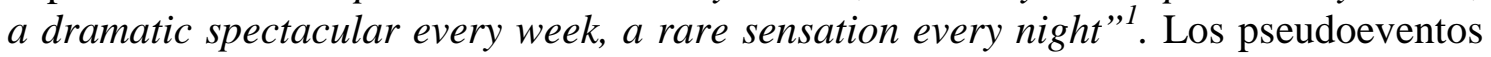
no son espontáneos, son planeados con el propósito inmediato de ser reproducidos, para lo que se llega a acuerdos tácitos con los medios de comunicación; son más dramáticos y vívidos, son más fáciles de diseminar y repetir. Como elementos basados en la imagen, son sintéticos, creíbles, pasivos (se pueden adaptar a diversas situaciones y contextos) y simples. Los pseudoeventos sustituyen a la propaganda en las sociedades altamente informadas. Muchas veces, el llamado "mercado libre de las ideas" consiste sólo en la competición entre diversos eventos preparados de antemano. En situaciones

\footnotetext{
* Doctor en Periodismo por la Universidad de Santiago de Compostela (USC), España.

${ }^{1}$ BOORSTIN, D.J. The Image, a guide to pseudoevents in America. Vintage Books. New York. 1992.
} 
de crisis, las llamadas explosiones (Gomis) o event-driven news (Regina Lawrence), los periodistas buscan rápidamente las fuentes oficiales, que de este modo mantienen el mismo control que ejercen sobre los pseudoeventos. En un hecho impredecible, lo único predecible es el control de las fuentes oficiales sobre la información.

Las campañas electorales se juegan en los medios de comunicación, y dependen sobre todo de la televisión ${ }^{2}$, abundando las teorías y los estudios sobre la llamada videomalaise o media malaise, pues los medios son vistos hoy como parte del problema, no de la solución. El éxito de la televisión tiene su origen en que simplifica drásticamente la política moderna, es eminentemente visual, autoritaria, toma prestados elementos de los programas de entretenimiento, y no solicita de sus consumidores nada más que atención. Hay que tener en cuenta que un telediario de media hora contiene menos información textual que la primera página de un periódico de formato sábana, y además está formado exclusivamente por titulares y leads, no profundiza en las cuestiones. Como afirma Sartori, "la televisión produce imágenes y anula conceptos, y de este modo atrofia nuestra capacidad de abstracción y con ella toda nuestra capacidad de entender".

En los últimos años se viene produciendo una reacción contra la idea de que el público masivo está tan pobremente informado que sus opiniones carecen de contenido político real. Seguramente debemos hablar, en cambio, de una racionalidad de baja información, de las formas en que los votantes emplean atajos cognitivos para tomar sus decisiones políticas y para basar sus tomas de posición. En este sentido, Campbell afirma que, en general, los electores deciden su voto en función de atajos cognitivos, o cognitive short-cuts ${ }^{3}$, proporcionados en gran medida por los medios de comunicación. Por lo tanto, la gran masa de votantes dispone de una información limitada pero suficiente para decidir su voto; como decía Gamson en Talking Politics, los ciudadanos no son tan tontos ni están tan mal informados. Del mismo modo, la opinión pública es vista por muchos teóricos como creada de arriba a abajo, formada por las elites que controlan el flujo de información, y seguramente es así en la mayor parte de los casos. Sin embargo, hay ocasiones en que no sucede así, emergiendo los cambios desde abajo.

Este conjunto de prácticas y actitudes políticas se desarrolla en un nuevo tipo de sociedad, postmoderna, nacida en las últimas décadas y que se encuentra en constante transformación. La postmodernidad está caracterizada por la desindustrialización y por la transición hacia la sociedad de la información. Asimismo, se producen cambios profundos en otros campos: observamos una progresiva desterritorialización de las relaciones sociales y del gobierno, así como una mayor transnacionalización de la política; finalmente, desaparecen las fronteras entre las esferas públicas y privadas de la vida. Para Marx, la conciencia, en cualquier sociedad, tiende a no representar la realidad, sino a ser un reflejo ideológicamente deformado de las realidades ocultas de la economía. Siguiendo este pensamiento, para Jameson el postmodernismo constituye la lógica cultural del capitalismo tardío. Desde hace años todo se relativiza, rechazándose los discursos totalizadores y dogmáticos propios de siglo $\mathrm{XX}$, y renunciándose a los "enunciados verdaderos" y el acceso a la totalidad.

La postmodernidad se define por las características de flujo frente a narración, la desconexión frente a la conexión, la aleatoriedad frente a la secuencia, la cultura amnésica frente a la memoria. La realidad, en cualquier terreno, pierde substantividad, peso, posición, totalidad, para comenzar a fragmentarse. Todo cambia, todo se convierte

\footnotetext{
2 No obstante, cada vez más autores se muestran escépticos sobre el concepto de americanización, prefiriendo analizar las nuevas características de las campañas como readaptaciones de los modelos tradicionales propios.

${ }^{3}$ CAMPBELL, A. et al. The American voter: an abridgement. John Wiley, cop. New York. 1964.
} 
en proceso, de forma que podemos decir que lo único inmutable en las sociedades postmodernas es la mutación. Prima la imagen, lo hiperreal. De este modo, la fantasía y las imágenes resultan más reales que la realidad misma ${ }^{4}$. Las imágenes son sintéticas, pasivas, creíbles, vívidas, concretas y simples. Experimentamos a la gente que sale por la televisión como si estuviesen a menos de un metro de distancia; incluso en la vida real esa es una distancia emocional, personal. Estamos seducidos por el mundo hiperreal de puras imágenes flotantes, detrás de las cuales no existe nada. Y puesto que nunca conoceremos las verdades ocultas tras las representaciones, es mejor aceptar que vivimos en un mundo de apariencias, o simulacro (Baudrillard). Como afirmaba Moles, "las innumerables ventanas, por las cuales las terminales les permiten a los hombres acceder a las redes son ventanas cerradas. No permiten más que el paso de apariencias, de las imágenes de un teatro del mundo en el que cada individuo juega anónimamente una obra que lo supera" . Hemos pasado del ser al estar, y ahora vivimos en el parecer: el mundo real queda enterrado, ignoto tras la realidad aparencial que los medios nos facilitan con normalidad y habitualidad.

\section{Reconexión de la ciudadanía}

Sin embargo, en los últimos años se viene produciendo un proceso de reconexión de los ciudadanos, así como un redescubrimiento de la comunidad, con el surgimiento de nuevas comunidades, en muchos casos sin una base geográfica. En este fenómeno los nuevos medios electrónicos y las posibilidades de comunicación online cumplen un papel muy importante, permitiendo la conversión de simples grupos de interés en nuevos movimientos sociales y generando nuevos tipos de sociedades en red, interconectadas y activas. No obstante, se cometen numerosos errores a la hora de analizar estos grupos e interrelaciones sociales, y en la actualidad continúan empleándose los mismos conceptos sobre formación y acción de grupos sociales que en los años cincuenta. Pero las sociedades contemporáneas han cambiado mucho, y los grupos son muy distintos. Así, en muchos casos, grupos de interés muy activos se han transformado en nuevos movimientos sociales. Por lo tanto, el activismo social no está muerto, sino que ha evolucionado hacia un espectro de formas muy diverso (Tarrow ${ }^{6}$ ). Mediante protestas ${ }^{7}$, los activistas definen como problemáticas ciertas situaciones que antes eran consideradas normales y que en consecuencia no acaparaban la atención pública y política. Los nuevos movimientos sociales persiguen el reconocimiento político de sus demandas y para eso también necesitan la persuasión, el cambio y la movilización del consenso social; lo primero implica entrar en la agenda política, lo segundo requiere el acceso a la agenda de los medios. La atención institucional a ciertas demandas no siempre depende del número de afectados o del nivel de agravio. El interaccionismo simbólico defiende que la clave reside en el éxito que alcanzan las interpretaciones de ciertas situaciones como injustas o indeseables. Es decir, la gravedad objetiva de los problemas resulta menos importante que la definición que de ellos hagan los medios de comunicación.

\footnotetext{
${ }^{4}$ Como ya anticipó Boorstin en The image.

${ }^{5}$ SAPERAS, Enric. La Sociología de la comunicación de masas en los Estados Unidos: una introducción crítica. Promociones y Publicaciones Universitarias. Barcelona. 1992.

${ }^{6}$ TARROW, S. Poder en Movimiento. Alianza Editorial. Madrid. 1997.

${ }^{7}$ Acciones como los flashmobs se convierten en un instrumento fundamental a emplear polos nuevos, movimientos sociales; alcanzan en primer lugar el llamado "anillo militante", para involucrar posteriormente al resto de la sociedad.
} 
Caminamos hacia una sociedad en red, interconectada, en la que las nuevas tecnologías favorecen la creación de nuevas comunidades ${ }^{8}$, que por supuesto son comunidades activas. En el siglo XVIII Tocqueville se asombraba de la actividad y riqueza de la sociedad civil de las colonias norteamericanas, y de la capacidad de sus ciudadanos para organizarse al margen del Estado: "tan pronto como varios habitantes de Estados Unidos conciben un sentimiento o una idea que quieren dar a conocer al mundo, se buscan. Y cuando se encuentran, se unen. Desde ese momento ya no son individuos aislados, sino un poder que se ve de lejos. De esta manera el ejemplo de cooperación civil puede dotar a los ciudadanos de un sentimiento de interdependencia y de poder. Con eso entrenan al pueblo en la práctica de la ciudadanía"9. Hoy este comentario podría hacerse sobre las nuevas comunidades que surgen al amparo de la red, al margen de los poderes públicos y al margen de las empresas y de las viejas agrupaciones sociales. La existencia de una comunidad implica un conocimiento compartido, la conciencia de pertenecer a ese grupo, y un sentido de obligaciones igualmente compartidas. En este nuevo modelo de estructuración social cobra protagonismo la sociedad civil, definida por Walzer como "espacio de asociación humana no coercitivo" y también como "el entramado de redes basadas en la relación que ocupan ese espacio" "10. La sociedad civil existe al margen del Estado, de los poderes públicos, pero constituye también una superación del individualismo ${ }^{11}$ y del poder de las empresas privadas. Tocqueville hizo esa misma diferenciación entre el individualismo y la poderosa sociedad civil que detectó en el nuevo mundo: "el individualismo, al inicio, sólo ciega las virtudes públicas, pero con el tiempo ataca y destruye todas las otras y acaba cerrándose en el egoísmo". Los grupos y entidades que componen el llamado Tercer Sector tienen hoy una oportunidad de incuestionable trascendencia, pues pueden expresar las preocupaciones ciudadanas, exigir responsabilidad de los poderes públicos, promover la comunidad, cubrir necesidades insatisfechas y, en general, mejorar la calidad de vida. Es decir, un Tercer Sector situado en las fronteras de los tradicionales actores que representan el Estado, el mercado y las redes primarias y que permite la apertura de espacios autónomos óptimos para impulsar acciones colectivas generadas desde la sociedad civil y, finalmente, hacer emerger esas redes sumergidas latentes propiciando la necesaria concertación de propuestas y opiniones para construir equilibrios dinámicos en las políticas económicas y las sociales.

\section{Nuevas posibilidades de comunicación}

En los últimos años las opciones de comunicación en red han provocado grandes cambios en los medios de comunicación, abriendo la posibilidad de vías alternativas de comunicación interpersonal y de masas ${ }^{12}$. En paralelo, se han agudizado una serie de crisis en el periodismo tradicional, cada vez más rutinario, próximo al poder y alejado de los ciudadanos. En consecuencia, producto de ambos factores, ha emergido un nuevo

\footnotetext{
${ }^{8}$ Podemos denominar comunidad a aquel espacio-tiempo abstracto donde nos encontramos seguros y compensados, compartiendo unos valores y un control en común.

${ }^{9}$ TOCQUEVILLE, Alexis. La Democracia en América. Aguilar. Madrid. 1990.

${ }^{10}$ WALZER, Michael. Toward a global civil society. Berghahn Books. Providence. 1995.

${ }^{11}$ Tocqueville auguró que "cada hombre, al ser igual de débil, sentirá igual necesidad de sus semejantes; y sabiendo que no puede obtener su apoyo sino a condición de prestar su concurso, descubrirá sin esfuerzo que para él el interés particular se confunde con el interés general" (Tocqueville, Alexis. Op. Cit. pág. 13).

12 Internet permite además una construción discursiva en estratos verticales (vertical layering); a través del hipertexto es posible la construcción de narraciones lineales, que a la vez permiten la profundización en la información o la presencia de múltiples fuentes y versiones enfrentadas.
} 
tipo de periodismo, realizado por y para la ciudadanía, que toma a Internet y a los medios electrónicos como soporte y que parte del principio de que los medios pueden contribuir a la vida pública, con filosofías que vuelven a poner de actualidad las teorías del public journalism. Este conjunto de prácticas ha recibido el nombre de Periodismo 3.0. En el Periodismo 3.0 es esencial el activismo social y se informa para influir en la realidad. Esto no es nuevo, por supuesto, el viejo periodismo político también lo hacía y más recientemente el periodismo cívico. Pero ahora Internet permite hacerlo a mucha más gente, con herramientas más potentes, mayor acceso a las fuentes, la posibilidad de mejorar el contenido en red (open source journalism) y una capacidad de difusión impresionante. Estas nuevas vías de comunicación permiten comunicarse y organizarse a los ciudadanos, anteriormente individuos en estado aislado, silenciosos, sin palabra, sin la capacidad ni el poder de hacerse oír.

La popularización de los weblogs (blogs) es el exponente más popularizado de este asalto ciudadano a los medios. El analista Juan Varela (periodistas21.blogspot.com) entiende los blogs como "identidades de dominio público""13, o egos digitales, que en contacto con otros usuarios pueden conformar comunidades virtuales, basadas en la inmediatez, la participación y el debate. Este yo digital rompe las barreras entre el espacio público y el personal, a través de una estrategia basada en la confianza. El asalto de los ciudadanos a la información y a la opinión rompe la autoridad de los medios, los periodistas y la comunicación normativizada; democratiza el periodismo, lo vigila y corrige, aunque también abre nuevas posibilidades a la manipulación. Se produce por lo tanto una crisis de la mediación, al desaparecer las fronteras entre comunicadores y audiencia. Esto es paradójico, puesto que la creciente complejidad de la sociedad obliga a una consecuente división del trabajo, y por lo tanto a la necesaria existencia de comunicadores profesionales. Sin embargo, la crisis de la mediación abre un infinito de participación exigente y enriquecedor para el avance del periodismo.

Por lo tanto, este nuevo fenómeno nace en un momento en el que el periodismo tradicional se halla en crisis a muchos niveles, además del ya referido de la mediación: crisis de objetividad, de autoridad (la gente se vuelve desconfiada y da la espalda a todas las instituciones reconocidas, entre ellas los medios), de información (popularización de formas de periodismo sectario y demagógico, por una parte, y de nuevos géneros híbridos en los que la información cada vez es presentada de manera más superficial: infotainment), de audiencia (por la fragmentación de audiencias), de atención (por la saturación provocada por la multiplicación de emisores) y de confianza, por el control que las fuentes oficiales y las grandes empresas ejercen sobre los contenidos difundidos por los medios (Gamson e Wolsfeld denunciaron que los medios contribuyen a una desigualdad acumulativa). Si el llamado mercado libre de las ideas funciona con los mismos criterios que todo mercado, los productores se ajustan a la demanda de quienes ofrecen un mejor precio por las informaciones. Por desgracia, no existen apenas análisis críticos del periodismo que se hace en España, fuera de las referencias a ciertos excesos llevados a cabo por la televisión. Hoy en día podemos hablar de una situación caracterizada por la sobreabundancia de información (que ya advertía Eco hace algunos años al hablar de la hiperinformación), por la multiplicación de los mensajes y la creciente complejidad y fragmentación del conocimiento, donde los esfuerzos de los periodistas deberían encaminarse hacia la calidad y la claridad en la representación de la actualidad, sobre la base de nuevos criterios que emanan hoy por hoy de la subjetividad de la audiencia: utilidad, selección, contextualización o cercanía.

13 VARELA, Juan. Xornalismo de cidadáns, un novo desafío para o xornalismo de calidade. En: http://consellodacultura.org/enblogs/?p=23. Ponencia presentada en Enblogs'06, Encontro de Blogs de Galicia e Portugal, Consello da Cultura Galega, Santiago de Compostela, 2006. 
Por su parte, los blogs suponen un emblema, un cliché afortunado que actúa como envoltorio popular del cambio social que se está produciendo. Pero no son sólo una moda, suponen un buen ejemplo de muchas de las características y cambios del nuevo tipo de sociedad. Los blogs tienen una historia corta y vertiginosa desde 1997, momento en el que Jorn Barger apuntó el término weblog por vez primera, pasando por el 2003, año de la gran efervescencia del fenómeno, derivada de la Guerra de Irak, hasta el momento actual, cuando la popularización de los blogs nos obliga a plantearnos si están provocando cambios de fondo en la sociedad. Quizás no sea la cantidad de blogueros (más de cien mil en todo el Estado español) lo más interesante, sino sus características cualitativas, que en este momento están cambiando: los usuarios de Internet están dejando atrás actitudes y usos más pasivos (consumo) para adoptar una posición más activa (producción). Para Fernando Garrido este salto "puede marcar el paso a la madurez de un país en el campo de la sociedad de la información"14.

Juan Varela entiende los blogs como una rebelión contra la acomodación y la estandarización del periodismo y contra el periodismo corporativo y su simbiosis con los poderes. El éxito de los blogs supone, en suma, un síntoma de la existencia de una crisis de la mediación. Afirma Manuel Bragado ${ }^{15}$, director de la editorial Xerais y uno de los más ilustres blogueros gallegos (sus brétemas están en la red desde enero de 2005) que Internet funciona como soporte (el medio es el mensaje, que decía McLuhan) de una nueva textualidad electrónica, una nueva literacidad: la forma de leer y escribir de cada tiempo. Si los blogs, a pesar de no ser medios informativos (es escasa la información en sentido estricto que podemos encontrar en ellos), son un exponente del llamado Periodismo 3.0, la nueva manera de hacer política y de que los ciudadanos influyan en los debates públicos puede ser denominada Política 3.0, basada en el glocalismo, la participación, la movilización virtual y una ética civil. Por lo tanto, la revolución de los weblogs es tan sólo un concepto, una denominación popular para un fenómeno más amplio y que no sólo afecta a la comunicación interpersonal o a la comunicación de masas. Es la sociedad en su conjunto la que está cambiando.

Esto no supone la desaparición del periodismo, ni la desaparición de los periodistas, sino de las instituciones periodistas tal como las entendemos hoy en día. En esta situación, los medios deben darse cuenta de que pueden contribuir a la vida pública, con valores y prácticas semejantes a los empleados por el public journalism. Entre otras cosas deben repensar las asunciones y las rutinas. Deben además escuchar a los lectores, ser parte de la comunidad, jugar más un papel de player y menos el de simple chronicler. Deben, por lo tanto, darles a los ciudadanos un mayor papel, reconectando a la gente, redescubriendo el concepto de comunidad y enterarse de que la ciudadanía es un verbo activo, y no consiste en la asunción automática de las decisiones dictadas desde el poder. No se trata de crear un nuevo tipo de periodismo, y por supuesto no existe una fórmula mágica, sino que hay que hacer muchas cosas bien, y hacerlas bien de principio a fin. Al igual que en la medicina, de donde proviene el concepto, lo que podríamos llamar periodismo holístico es el equivalente al buen periodismo, y por lo tanto, una vez que se realiza con eficacia pierde su nombre. Simplemente consiste en contar lo que pasa no sólo cuando sucede algo, sino antes: los procesos, la vigilancia, la denuncia. Las nuevas tecnologías suponen un fenomenal instrumento de organización y difusión de conocimiento e información y ayudan a la creación de espacios públicos de

\footnotetext{
${ }^{14}$ GARRIDO, Fernando. Como medra a sociedade blog. En:

http://consellodacultura.org/enblogs/?p=23. Ponencia presentada en Enblogs'06, Encontro de Blogs de Galicia e Portugal, Consello da Cultura Galega, Santiago de Compostela, 2006.

${ }^{15} \mathrm{http}: / /$ bretemas.blogspot.com
} 
debate. La ciudadanía debe forzar a las élites a enfrentarse a una oposición articulada, y a que esta lucha tenga lugar en campo abierto, en la esfera pública.

Pero, ¿pueden los medios electrónicos contribuir a mejorar el funcionamiento de la democracia? ¿Estamos asistiendo a una transformación en la forma en que la sociedad se organiza? La ciberdemocracia (también llamada democracia electrónica, netdemocracia o democracia digital) implica una nueva forma de práctica democrática y en ella se establecen asimismo nuevas formas de ciudadanía y de vida pública. Incluso Stefano Rodota plantea un cambio real de paradigma, acuñando el término de democracia continua. Ya en 1979 Michael Margolis vislumbraba una democracia viable (viable democracy) de intenso intercambio comunicativo, con la única condición de que las instituciones políticas incorporasen este intercambio comunicativo a su funcionamiento desde una sincera perspectiva democratizadora. La función social del periodismo se basa en la convicción en dos máximas: que la función de los periodistas es informar a los ciudadanos, que unos ciudadanos bien informados contribuyen a un mejor funcionamiento de la democracia. Cuando los liberales del siglo XIX calificaban el sistema que se estaba configurando como "régimen de opinión" no pensaban sólo en la función legitimadora de la opinión pública expresada a través de los procesos electorales, ni en la función mediadora entre instituciones y corrientes de opinión llevada a cabo por la prensa, sino sobre todo en la función de crítica política ejercida por los medios de comunicación y los ciudadanos, sin la que no puede existir un gobierno responsable y sometido a controles.

Con todo, autores como Mazzoleni restan importancia a la supuesta reconversión, calificándola de mera "revolución simbólica"16. Una de las razones es que el conjunto de ciudadanos que participa en la comunicación política a través de la red sigue siendo una minoría, probablemente coincidente con la misma minoría que por vías tradicionales ya constituía el reducido público atento de nuestras débiles democracias. Además, la actual democracia institucionalmente delegada y elitista es capaz de reabsorber, para su propia conservación, las nuevas vías de comunicación sociopolítica que la interactividad apuntaba. Por lo tanto, es necesario reflexionar sobre las consecuencias efectivas que esta participación ciudadana a través de los medios electrónicos puede tener en el funcionamiento del sistema. Las nuevas tecnologías no son una panacea, dado que los problemas de la democracia son de raíz cultural antes que tecnológica, con lo que difícilmente Internet podrá por sí sólo alterar los hábitos sociales.

\section{Conclusiones}

La pregunta que debe hacerse es si estamos asistiendo a un proceso de gran impacto en nuestras sociedades, algo así como una revolución, o si las distintas posibilidades tecnológicas, y los cambios de hábitos y actitudes que consecuentemente provocan suponen una moda, simples transformaciones cosméticas. ¿Moda $\mathrm{O}$ revolución? Seguramente ambas cosas a un tiempo: muchos de sus fenómenos constituyen modas pasajeras y son sustituidos sucesivamente por manifestaciones similares. Pero asistimos igualmente a una revolución, un cambio profundo en las formas de comunicación de los individuos, que está provocando ya transformaciones en los hábitos, estructuras sociales, mecanismos de formación de grupos, acción de movimientos sociales y vías de participación política. Los nuevos medios electrónicos no van a sustituir a los medios tradicionales, coexistirán con ellos, y además provocarán

${ }^{16}$ DE BENS, E. y MAZZOLENI, G. The Media in the Age of Digital Communication. Págs. 75-94. En: MCQUAIL, D. y SIUNE, K (eds.). Media Policy, Converge, Concentration and Commerce. Sage. London. 1998. 
(ya lo están haciendo) transformaciones en los contenidos, formas de producción y hábitos de consumo de prensa, radio y televisión. Fuera de estos cambios, conviene preguntarse la incidencia que estos cambios generados por las mayores posibilidades de conexión en red pueden tener en las formas de organización política y en las vías de participación democrática y deliberación cívica de los asuntos públicos. La ecuación de mayor conexión igual a mayor participación y a más democracia puede hacerse cierta en cuanto un porcentaje significativo (superior al actual) de la población se habitúe a utilizar estos medios para expresar su voz, relacionarse con comunidades afines a su ideología y pensamiento, y participar en las deliberaciones públicas. Entonces, podrá hablarse de que la ciberdemocracia ha sacado a las sociedades desarrolladas de su apatía y cinismo político, y ha convertido a las escleróticas democracias avanzadas en verdaderas democracias deliberativas.

\section{Referencias bibliográficas}

DE BENS, E. y MAZZOLENI, G. The Media in the Age of Digital Communication. En: MCQUAIL, D. y SIUNE, K (eds.). Media Policy, Converge, Concentration and Commerce. Sage. London. 1998.

GARRIDO, Fernando. Como medra a sociedade blog. En: http://consellodacultura.org/enblogs/?p=23. Ponencia presentada en Enblogs'06, Encontro de Blogs de Galicia e Portugal, Consello da Cultura Galega, Santiago de Compostela, 2006.

TARROW, S. Poder en Movimiento. Alianza Editorial. Madrid. 1997.

TOCQUEVILLE, Alexis. La Democracia en América. Aguilar. Madrid. 1990.

VARELA, Juan. Xornalismo de cidadáns, un novo desafío para o xornalismo de calidade. En: http://consellodacultura.org/enblogs/?p=23. Ponencia presentada en Enblogs'06, Encontro de Blogs de Galicia e Portugal, Consello da Cultura Galega, Santiago de Compostela, 2006.

WALZER, Michael. Toward a global civil society. Berghahn Books. Providence. 1995. 